\title{
Postulaciones políticas en la novela Noticia de un secuestrode Gabriel García Márquez
}

Politics applications in the novel Noticia de un secuestro by Gabriel García Márquez

\section{Resumen}

Este artículo está basado en la investigación "Postulaciones políticas en la novela colombiana del siglo XX" de la Universidad Cooperativa de Colombia, sede Bucaramanga, 2009, que inició en el segundo semestre del 2009 y finalizó en el primer semestre del 2011. Para este caso específico, se trabajó con la novela Noticia de un secuestro de Gabriel García Márquez, autor colombiano que nace en la región Caribe en el municipio de Aracataca (Magdalena) el 6 de marzo de 1927.

Esta obra nos muestra la problemática política colombiana del siglo XX y una serie de secuestros ocasionados por los llamados "extraditables" con el fin de evitar su extradición.

Palabras clave Narcotráfico, secuestro, violencia.

Abstract

This article is based on research into "Political proposals in the Colombian novel of the twentieth century" of Universidad Cooperativa de Colombia, Bucaramanga, 2009, this research began in the second semester of 2009 and it ended in the first semester of 2011. Specifically we work on the novel Noticia de un secuestro by Gabriel Garcia Márquez, - a Colombian writer who was born in the Caribbean region in the municipality of Aracataca (Magdalena) March 6th, 1927. This work shows the problem of the twentieth century Colombian politics and a series of kidnappings caused by so-called "extraditable" to avoid extradition.

Keywords Drug trafficking, kidnapping, violence.
Ketty-Hassell Lebethe* Mónica-Patricia Toloza**: Neyla-Johanna Villarreal ${ }^{* * *}$

Docente que avala el artículo: Jairo Castro Neira ${ }^{\text {\%*\%** }}$

Recibido: 4 de marzo del 2011 Aprobado: 18 de abril del 2011

Cómo citar este artículo: Lebethe, KettyHassell; Toloza, Mónica-Patricia y Villarreal, Neyla-Johanna (2011), "Postulaciones políticas en la novela Noticia de un secuestro de Gabriel García Márquez", en Rastros Rostros, vol. 13, núm. 25, pp. 103-107.

* Estudiante de Licenciatura en Educación Básica con énfasis en Humanidades, Lengua Castellana e Inglés de la Universidad Cooperativa de Colombia, sede Bucaramanga. Correos electrónicos: ketty.lebethe@campusucc.edu.co. kettylebethe@hotmail.com

** Estudiante de Licenciatura en Educación Básica con énfasis en Humanidades, Lengua Castellana e Inglés de la Universidad Cooperativa de Colombia, sede Bucaramanga. Correos electrónicos: monica.toloza@campusucc.edu.co, lolalola20@hotmail.com

*** Estudiante de Licenciatura en Educación Básica con énfasis en Humanidades, Lengua Castellana e Inglés de la Universidad Cooperativa de Colombia, sede Bucaramanga. Correos electrónicos:_neila.villarreal@campusucc.edu.co, neilita_villarreal@hotmail.com

***** Licenciado en Idiomas de la Universidad Industrial de Santander. Magíster en Semiótica (Tesista) de la Universidad Industrial de Santander. Docente de la Universidad Cooperativa de Colombia, sede Bucaramanga. Correo electrónico:jairo.castro@campusucc.edu.co 


\section{Introducción}

abriel García Márquez, en su obra Noticia de un secuestro (1996), narra las desesperadas medidas adoptadas por un grupo de delincuentes colombianos denominados "los extraditables" y cuenta los diferentes sucesos de violencia y desesperanza de la Colombia de los años noventa. Este artículo presenta el proceso de investigación construido a partir de la novela mencionada, y se enmarca dentro del macro proyecto de investigación formativa titulado "Postulaciones políticas en la novela colombiana del siglo XX", desarrollado la Licenciatura en Educación básica con énfasis en Humanidades, lengua castellana e inglés de la Universidad Cooperativa de Colombia, sede Bucaramanga.

La investigación está dividida en tres capítulos, tomando como referencia a Paul Ricoeur y su teoría de tiempo y narración (Ricoeur, 1983, pp. 85-136). El primero aborda tiempo y espacios de experiencia en los que se desarrolla la novela y la relación existente entre éstos y los espacios de experiencia del autor. En el segundo capítulo, se analiza a fondo la temporalidad narrativa en la novela enfocada en el orden de la narración, llevando una línea del tiempo para poder determinar las analepsis presentes en ella. El tercer capítulo desarrolla el propósito de la investigación: plantear una propuesta pedagógica que busca, por medio de la foto novela, motivar a la lectura crítica de obras literarias en los planteles de educación básica y media en Bucaramanga.

\section{Metodología}

Es necesario conocer que Paul Ricoeur expone su teoría de la mímesis (1983, pp. 85-136) a partir de tres momentos del relato:

Mímesis I. Tanto en el autor, como en el lector hay una precomprensión común del obrar humano. Se desarrolla la mímesis de la obra desde el análisis de lo prefigurado, de la realidad a partir de la cual el autor crea su obra.
Mímesis II. Es la mediación entre la mímesis I (la precomprensión del mundo) y la mímesis III (la comprensión posterior en la lectura). Parte de que toda obra representa la imitación de una acción y eso lo hace a la manera de una configuración.

Mímesis III. Corresponde a los que Gadamer llama hermenéutica de la aplicación (Ricoeur, 1983, p. 31). La lectura es, otra vez, una refiguración en el tiempo, pero la lectura no es algo aséptico, pues la obra habla principalmente de mí mismo.

El primer capítulo, mímesis I, parte de los espacios de experiencia del autor y su obra, en este caso, Noticia de un secuestro del escritor colombiano Gabriel García Márquez, cuya trama plasma una problemática política colombiana real que ha azotado al país desde hace algunos años y que, como todas las situaciones planteadas en ella, tiene implicaciones en la situación actual del país.

Gabriel García Márquez es un periodista, escritor y guionista colombiano, nacido en el municipio de Aracataca (Magdalena) el 6 de marzo de 1927, hijo de Gabriel Eligio García y de Luisa Santiaga Márquez Iguarán. Poco después del nacimiento de Gabriel su padre se convirtió en farmacéutico y, en enero de 1929, se mudó con Luisa a Barranquilla, dejando a Gabriel en Aracataca al cuidado de sus abuelos maternos. Dado que vivió con ellos durante los primeros años de su vida, recibió una fuerte influencia del coronel Márquez quien era un liberal veterano de la Guerra de los Mil Días, muy respetado por sus copartidarios y conocido por su negativa a callar sobre la Masacre de las bananeras. Estudiante de derecho, inmediatamente después del Bogotazo (el asesinato del dirigente liberal Jorge Eliecer Gaitán) comenzó sus colaboraciones en el periódico liberal El Universal.

Noticia de un secuestro aborda los temas del narcotráfico y la pérdida de la libertad, basados en hechos ocurridos en la realidad colombiana. Esta historia se inicia con el secuestro de las respetadas periodistas Maruja Pachón y Beatriz Villamizar de 
Guerrero, quien es la cuñada de Maruja y su asistente personal, el 7 de noviembre de 1990. Popularmente se cree que Maruja fue raptada por ser hermana de Gloria Pachón, viuda del periodista y fundador del Nuevo Liberalismo Luis Carlos Galán. El libro examina la primera de una serie de secuestros relacionados entre sí: el 30 de agosto de 1990, Diana Turbay, directora del programa de noticias Criptón y la revista Hoy x Hoy, había sido secuestrada junto a otros cinco miembros de su noticiero. Estos incluyen a la editora Azucena Liévano, el escritor Juan Vitta, a los operadores de cámaras Richard Becerra y Orlando Acevedo, y al fotógrafo alemán Hero Buss. La periodista es hija del ex presidente colombiano y líder del Partido Liberal Julio César Turbay. También fue secuestrado en este episodio Francisco "Pacho" Santos. Después de que estas personas perdieran su libertad, sus familiares son informados y sólo les resta esperar noticias a través de los principales medios de comunicación: radio y televisión. Alberto Villamizar, quien es esposo y hermano de dos de las víctimas, Maruja Pachón y Beatriz Villamizar, preocupado por la suerte de sus familiares logra, de cierta forma, intervenir en esta dramática situación y pide al gobierno que no actúe sin antes comunicarle todo lo concerniente al posible rescate de su esposa y hermana.

Como antagonistas en la historia, encontramos al Cartel de Medellín. Los narcotraficantes de la época de Pablo Escobar, protagonistas de las diversas situaciones adversas que atravesaba Colombia, tales como los secuestros, los homicidios selectivos y los atentados a las entidades del gobierno, temían la pena máxima a sus delitos, la cual consistía en ser extraditados a los Estados Unidos para ser juzgados por sus culpas. Por ello eligen la modalidad del secuestro para presionar al gobierno local y evitar las extradiciones. La crueldad del secuestro es la protagonista de esta obra y del imaginario de los colombianos de dicha época, ya que a pesar de que finalmente los secuestrados logran ser liberados y entregados a sus familiares, la tristeza y violencia de estos hechos siguen siendo parte de la historia Colombiana y que se adoptan en la obra de García Márquez.

El segundo capítulo, mímesis II, aborda el tiempo de la obra, entendido como la ordenación temporal del relato en relación con la historia, y es por esto que se hace necesario desarrollar una línea del tiempo.

La historia parte de un momento desde el cual se establece un primer relato que servirá para determinar las respectivas analepsis, que son los recuerdos o evocaciones que se trabajan. Diferenciaremos las analepsis internas (posteriores a los días del secuestro) y las analepsis externas (anteriores a estos días). Algunas de estas analepsis tienen una función completiva y permiten llenar un vacío dejado por el relato, otras tienen una función claramente repetitiva y sirven para poner el énfasis en unos acontecimientos particularmente importantes. Estamos aquí ante fenómenos de frecuencia.

Noticia de un secuestro se presenta como el relato cronológico en presente de una historia que comienza con el rapto de Maruja Pachón y Beatriz Villamizar de Guerrero la tarde del 7 de noviembre de 1990 (García Márquez, 1996, pp. 9-22) y se concluye con el final de la noticia más no necesariamente de los secuestrados, puesto que dos de éstos murieron y ocho quedaron libres y vivos. La acción es muy reducida: el único fin verdadero de Pablo Escobar y el grupo de extraditables es lograr la no extradición, y para lograrlo emprenden una ola de secuestros a periodistas con el fin de presionar al Gobierno. El presente de la acción se reduce a los menudos hechos de la vida diaria de aquellos secuestrados:

Ya no pedían permiso para levantarse, y cada quien se servía su café o cambiaba los canales de televisión. Lo que se hablaba dentro del cuarto seguía siendo en susurros pero los movimientos se habían vuelto más espontáneos. Maruja no tenía que sofocarse con la almohada para toser, aunque tomaba precauciones mínimas para que no la oyeran desde

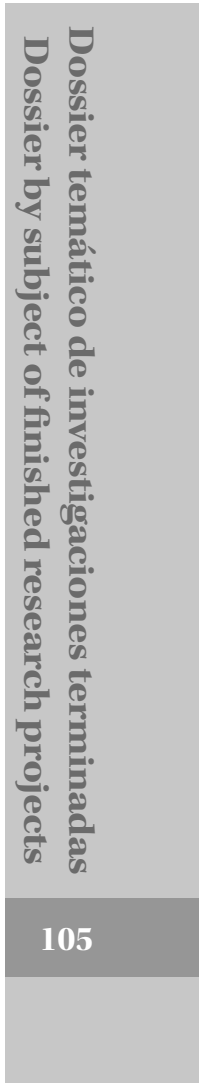

Revista Rastros Rostros - Volumen 13, Número 25 - enero-junio 2011 
afuera. El almuerzo y la comida seguían siendo iguales, con los mismos frijoles, las mismas lentejas, las mismas piltrafas de carne reseca y una sopa de paquete ordinario. Los guardianes hablaban mucho entre ellos sin más precauciones que los susurros. Se intercambiaban noticias sangrientas, de cuánto habían ganado por cazar policías en las noches de Medellín, de sus proezas de machos y sus dramas de amor. Maruja había logrado convencerlos de que en el caso de un rescate armado era más realista que las protegieran para asegurarse al menos un tratamiento digno y un juicio compasivo (García Márquez, 1996, p. 117).

Algunas de las acciones con las que los secuestrados tratan en vano de romper esa rutina son algunos recuerdos: "Diana se desahogó con Hero Buss. Le habló de su depresión por haberlos llevado a la trampa sin salida en que se encontraban, le confesó que estaba tratando de apaciguar los recuerdos de familia -su esposo, sus hijos, sus padres-, que no le daban un instante de tregua. Pero el resultado era siempre el contrario" (García Márquez, 1996, p. 39).

Noticia de un secuestro es todo lo contrario de una novela de acción. Lo que importa es la vida interior de los personajes, son sus recuerdos y sus vivencias.

Finalmente, en el capítulo III, la mímesis III, se presenta una propuesta pedagógica que tiene como fin llevar la literatura al aula de clase por medio de la obra Noticia de un secuestro, fundamentada en la solución de problemas, partiendo de que: "el término problema designa una dificultad que no puede resolverse automáticamente, sino que requiere una investigación, conceptual o empírica” (Bunge, 1972, p. 85).

Siempre ha existido una dicotomía en la enseñanza de la literatura, pues hay quienes piensan que no existe manera de enseñar a través de ella y quienes mencionan que la literatura es sólo para leer y que no puede tener otra función. La literatura es más que arte y, más allá de leerla, cumple el papel educativo de formar para la libertad (Cárdenas, 1994, p. 129). Creemos que, más que escribir un texto para que las personas lean, se busca que a través de la lectura se transformen pensamientos, sentimientos, situaciones, entre otras. Ésta es, a nuestro modo de ver, una de las funciones de la literatura, permear los pensamientos de las personas para que estas transformen el mundo. La literatura cumple un papel fundamental que va en función de la formación de las personas. Por tal razón no se debe encasillar su lectura solamente en términos de comprensión.

El lector debe estar preparado para enfrentarse al mundo-texto de manera activa, plural, crítica, creativa, vital, competente y contemporánea, y de superar los hábitos escolares de la lectura literal (Cárdenas, 1997, pp. 39-41).

\section{Resultados}

A partir de la literatura colombiana, buscamos incentivar a los estudiantes para que, por medio de la lectura, desarrollen su comprensión lectora y un sentido analítico y crítico, despertando en ellos el interés por la investigación, pero también un sentido de reflexión.

Por otra parte, también se busca conocer las diferentes situaciones de la vida cotidiana para formar estudiantes capaces de proponer nuevas alternativas frente a los conflictos del país.

El proyecto de aula es una propuesta didáctica enfocada a la solución de problemas, por medio de procesos formativos que se inician a partir de las siguientes preguntas realizadas a los estudiantes:

¿Qué es lo que se torna aburrido a la hora de leer un libro?, ¿cuántos textos literarios lees durante el año en tu salón de clase?, ¿lees las obras literarias recomendadas por tu profesor?, ¿escogerías obras literarias colombianas para leer dentro del salón de clase?, ¿qué crees que podrías hacer cuando lees obras literarias colombianas y conoces las problemáticas de nuestro país?

Después de realizado el cuestionamiento, los estudiantes contextualizan términos como política, narcoterrorismo, secuestro, entre otros, por medio 
de espacios en los que se les permita, con diversas actividades, comprender y enfocar su atención a lo que queremos lograr en ellos: el análisis de la novela Noticia de un secuestro.

Muchas de las costumbres que se practican en las aulas de clase tienen que ver con el hecho de leer libros enfocándose solamente en la comprensión lectora, olvidando que desde los textos literarios se pueden abordar aspectos que llevan a tocar la realidad de los lectores: valores, situaciones familiares, problemas de un país, situaciones de la vida cotidiana.

Como producto final, por medio de la fotonovela los estudiantes darán a conocer el trabajo que realizaron con la obra.

\section{Conclusiones}

Con la lectura de obras literarias los estudiantes pueden reflexionar acerca de la situación en la que se encuentra Colombia y cómo, en algunas ocasiones, ésta no varía a pesar del paso del tiempo.

La fotonovela es una estrategia que puede ayudar en la lectura de una obra literaria, dado que permite tener una coherencia con la obra y el aporte de cada estudiante.

\section{Referencias}

Bunge, M. (1972), La investigación científica, su estrategia y su filosofía, Barcelona, Siglo XXI.

Cárdenas, A. (2004), Elementos para una pedagogía de la Literatura, vol. 4, Bogotá, Universidad Pedagógica Nacional.

García Márquez, G. (1957), Noticia de un secuestro, Editorial Mondadori, 1996.

Genette, G. (1989), Figuras III, Barcelona, Lumen.

Ricoeur, P. (1995), Tiempo y narración, México, Siglo XXI. 
